\title{
Interleukin-15 is a potent survival factor in the prevention of spontaneous but not CD95-induced apoptosis in CD4 and CD8 T lymphocytes of HIV-infected individuals. Correlation with its ability to increase BCL-2 expression
}

\author{
Honami Naora ${ }^{1}$ and Marie-Lise Gougeon ${ }^{\star, 1}$ \\ 1 Unité d'Oncologie Virale and URA CNRS 1930, Departement SIDA et Retrovirus \\ Institut Pasteur, 28 Rue du Dr. Roux, 75724 Paris, Cedex 15, France \\ * corresponding author: M.-L. Gougeon, Unité d'Oncologie Virale and URA \\ CNRS 1930, Departement SIDA et Retrovirus, Institut Pasteur, 28 Rue du Dr. \\ Roux, 75724 Paris, Cedex 15, France. \\ tel: 331456889 07; fax: 331456889 09; \\ e-mail: mlgougeo@pasteur.fr
}

Received 5.3.99; revised 17.6.99; accepted 10.8.99

Edited by R. Knight

\begin{abstract}
IL-15 shares many biological properties with IL-2, a cytokine whose administration to HIV-infected individuals has been effective in enhancing depleted CD4 T lymphocyte numbers. The present study examined whether exogenous IL-15 could protect lymphocytes of HIV-infected individuals from spontaneous apoptosis, associated with growth factor deprivation, and CD95-induced apoptosis, which is believed to play a major role in T lymphocyte loss and HIV pathogenesis. Although IL15, like IL-2, failed to inhibit CD95-induced lymphocyte apoptosis in vitro, IL-15 was found to act as a potent survival factor in the prevention of spontaneous apoptosis. The greater enhancement of lymphocyte survival, promoted by IL-15 as compared with IL-2 when used at an equivalent concentration, was associated with higher up-regulation of bcl-2 expression. In addition, IL-15 was more potent than IL-2 in stimulating lymphocyte proliferation. Despite the strong ability of IL-15 to promote both lymphocyte survival and proliferation, the increases in representation and total numbers of viable cells induced by IL-15 were not higher than those induced by IL-2. This appears to be associated with the greater ability of IL-15 to activate lymphocytes and increase their apoptosis-susceptibility. Therefore, lymphocyte loss occurring by growth factor deprivation in HIV infection may be potentially prevented by IL15 , although its benefits for survival need to be closely assessed against its ability to augment lymphocyte activation.
\end{abstract}

Keywords: interleukin-15; HIV; apoptosis; $\mathrm{CD}^{+}$and $\mathrm{CD}^{+} \mathrm{T}$ lymphocytes; bcl-2

Abbreviations: 7-AAD: 7-amino actinomycin D; mAbs: monoclonal antibodies; MFI: mean fluorescence intensity; PCNA: proliferating cell nuclear antigen; PE: phycoerythrin

\section{Introduction}

IL-15 exhibits many activities in common with IL-2, including stimulating $\mathrm{T}$ cell proliferation, induction of cytolytic effector cells and NK cell activity. ${ }^{1-3}$ The overlapping biological activities of IL-15 and IL-2 are attributable to the utilization by these cytokines of two common receptor chains $\beta$ and $\gamma^{4}$ The two cytokines differ in their cellular sources. IL-2 is primarily produced by activated T cells, whereas IL -5 is expressed by a wide variety of cells and tissues such as activated monocytes, placenta, skeletal muscle, kidney, lung and heart. ${ }^{1,2}$

Administration of IL-2 to HIV-infected individuals has been shown to significantly enhance $\mathrm{CD} 4^{+} \mathrm{T}$ cell numbers. ${ }^{5}$ Although disadvantages of IL-2 therapy such as toxicity and enhanced HIV replication have been addressed, at least in part, by improved regimes involving lower IL-2 dosages and the combined use of anti-retroviral agents, recent attention has turned towards IL-15 as a possible alternative immunotherapy. Various reports indicate that $\mathrm{IL}-15$ has less of a stimulatory influence on HIV expression than IL$2 .^{6,7} \mathrm{IL}-15$ reportedly stimulates expansion of HIV-specific $\mathrm{CTL}^{8}$ and enhances activities of NK and LAK cells which are impaired in HIV-infected individuals. ${ }^{6,7}$ In addition, studies in mouse models indicate that $\mathrm{IL}-15$ has a therapeutic index superior to IL-2 when toxicity of these cytokines was assessed against their efficacy in inducing cytolytic activity. ${ }^{9}$ To date, most studies regarding the immunotherapeutic potential of IL-15 have focused on its ability to enhance cytolytic activities. However, little is known regarding the potential of $\mathrm{IL}-15$ to control lymphocyte apoptosis in HIV infection. While apoptosis plays essential roles in immune regulation, it can be pathogenic where it interferes with the generation and renewal of effector cells, as appears to be the case in HIV infection. ${ }^{10,11}$ The causes of lymphocyte apoptosis in HIVinfected individuals are multi-factorial and are believed to include TCR/CD3 triggering in the absence of appropriate co-stimulation, CD95-CD95 ligand interactions and gp120CD4 interactions. ${ }^{10,11}$ In addition, alterations in the profile of cytokine production and deprivation of growth factors arising from deletion of lymphocyte populations can contribute to further lymphocyte loss. ${ }^{11,12}$

Freshly isolated lymphocytes of HIV-infected individuals are highly susceptible to apoptosis following short-term culture in the absence of exogenous cytokines, commonly referred to as spontaneous apoptosis, and to apoptosis induced in vitro by mitogens, recall antigens and monoclonal antibodies (mAbs) directed against the CD3 and CD95 molecules. ${ }^{13-15}$ This marked apoptosissusceptibility is believed to be associated with the 
chronically activated state of lymphocytes of HIV-infected individuals. ${ }^{15}$ In contrast, lymphocytes of healthy, uninfected individuals do not exhibit a highly activated state ex vivo, and exhibit little or no spontaneous apoptosis and CD3- and CD95-induced apoptosis following culture. ${ }^{13-15}$ Various cytokines appear to influence apoptosis susceptibility. Exogenous IL-12 reportedly inhibits CD3and CD95-induced death of lymphocytes of HIV-infected individuals in vitro, ${ }^{16,17}$ whereas IL-2 protects against spontaneous apoptosis. ${ }^{18,19}$ In addition, recent studies found IL-15 to be more effective than IL-2 in protecting against lethal CD95-induced hepatic failure in mice. ${ }^{20}$ In view of the detrimental role which lymphocyte apoptosis plays in HIV pathogenesis, it was of interest in the present study to examine the effects of exogenous IL-15 on apoptotic death of lymphocytes of HIV-infected individuals. Although IL-15 appears to act as a potent survival factor in the prevention of spontaneous apoptosis, and also promotes lymphocyte proliferation, IL-15 failed to block CD3- and CD95-induced death, and its beneficial effects on survival and proliferation need to be considered against its ability to further increase the lymphocyte activation state.

\section{Results}

\section{Effect of exogenous IL-15 on apoptotic death of lymphocytes of HIV-infected individuals induced by anti-CD95 mAbs}

Our laboratory and other investigators have observed that freshly isolated lymphocytes of HIV-infected individuals undergo marked apoptosis when cultured overnight with mAbs against the CD95 molecule. ${ }^{14,22,25}$ In contrast, little or no anti-CD95-induced apoptosis has been observed in lymphocytes of uninfected persons. ${ }^{14,22,25}$ In preliminary experiments we observed that the level of apoptosis induced in PBMC of HIV-infected individuals with immobilized antiCD95 mAbs was stable from day $1-3$. In contrast, the proportion of apoptotic lymphocytes in cultures incubated in medium alone markedly accelerated after day 1 , as previously found, ${ }^{15}$ and approached the level observed in anti-CD95stimulated cultures by day 3. Effect of exogenous IL-15 on anti-CD95-induced apoptosis was therefore examined at day 1 , since perceived reductions in apoptosis in cultures incubated beyond day 1 would become increasingly likely to be attributable to cytokine-mediated rescue from spontaneous apoptosis.

PBMC were incubated for 1 day in the absence or presence of anti-CD95 mAbs, and apoptosis assessed by immunofluorescence analysis of 7-AAD-staining within $\mathrm{CD}^{+}$and $\mathrm{CD}^{+}$populations. Responses to exogenous $\mathrm{IL}-15$ were compared with those to IL-2, IL-12, and IL-10 at a final concentration of $10 \mathrm{ng} / \mathrm{ml}$, which have been previously studied. ${ }^{16,20,26}$ Although the level of apoptosis occurring spontaneously in medium alone at day 1 was much lower than that induced by anti-CD95 mAbs, a statistically significant reduction in spontaneous apoptosis was observed in both the $\mathrm{CD}^{+}$(Figure 1) and $\mathrm{CD}^{+}$(not shown) subsets by the addition of IL-15. Spontaneous
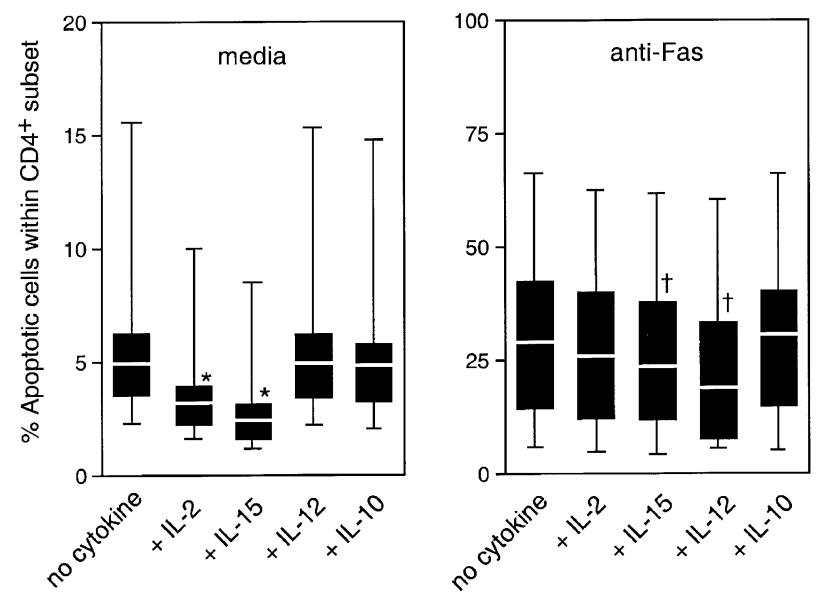

Figure 1 Differential effects of IL-15 and other exogenous cytokines on CD95-induced apoptosis. PBMCs of HIV-infected individuals were incubated for 1 day in the absence or presence of exogenous IL-2, IL-15, IL-12 and IL-10 at a final concentration of $10 \mathrm{ng} / \mathrm{ml}$ in uncoated wells, or in wells coated with immobilized anti-CD95 mAbs. Cells were stained with 7-AAD and either antiCD4 or anti-CD8 mAbs, and the percentage of 7-AAD-stained cells in each subset was determined by dual-colour immunofluorescence analysis. Shown are the median (25th-75th percentiles) values of apoptotic 7-AAD-stained cells within the $\mathrm{CD}^{+}$and $\mathrm{CD}^{+}$subsets of the patient group $(n=18)$. Statistical significance was assessed by the Wilcoxon's signed rank test for paired data. ${ }^{*} P<0.0005$, ↔ $P<0.05$

apoptosis was likewise reduced by IL-2 addition (Figure 1), as previously observed. ${ }^{18,19} \mathrm{IL}-12$ partially inhibited CD4 ${ }^{+} \mathrm{T}$ cell apoptosis induced by CD95-triggering, as reported by others. $^{16,17}$ Significant, but only modest, inhibition by IL-10 of anti-CD95-induced $\mathrm{CD}^{+} \mathrm{T}$ cell death was also observed (not shown), which could explain the partial inhibition found in one study ${ }^{27}$ and the weakness reported by others. ${ }^{26}$ Modest decreases in the proportion of apoptotic $T$ cells were detected in response to IL-15 and to IL-2 in antiCD95-stimulated cultures. However, such diminution was not consistently observed for all patients, and was only marked in lymphocytes of patients which also exhibited an appreciable reduction in spontaneous apoptosis in response to IL-15 and to IL-2 (Figure 1). This suggests that the perceived reduction in apoptosis in anti-CD95-stimulated cultures could be largely attributable to prevention by these cytokines of spontaneous death of lymphocytes which were otherwise not induced to die by CD95triggering.

\section{Inhibitory effect of exogenous IL-15 on spontaneous lymphocyte apoptosis}

The above findings indicated that exogenous IL-15 neither directly nor strongly inhibits CD95-induced death of lymphocytes of HIV-infected individuals, but could potentially protect lymphocytes from spontaneous apoptosis. Although the reduction in spontaneous apoptosis by IL-15 was statistically significant, the level of spontaneous apoptosis seen in the absence of exogenous cytokines at day 1 was not appreciably high. Addition of IL-15 at $10 \mathrm{ng} /$ $\mathrm{ml}$ clearly reduced the level of spontaneous apoptosis within the $\mathrm{CD}^{+}$subset, as indicated by the reduced 
percentage of 7-AAD-stained cells (Figure 2B) and the reduced pool of cells exhibiting small size and high granularity (Figure 2C). Exogenous IL-15 was more effective in reducing the percentage of apoptotic cells within the $\mathrm{CD}^{+}$subset than within the $\mathrm{CD}^{+}$subset, as was likewise observed for IL-2 (Figure 2A,B). Effects of cytokines were also compared at different concentrations ranging from 1 to $100 \mathrm{ng} / \mathrm{ml}$. IL-15 was more effective than IL-2 in reducing spontaneous apoptosis, particularly within the CD8 subset at lower concentrations of the range tested, and less effective at higher concentrations (Figure $3 A, B)$. Co-stimulation with $\mathrm{IL}-15$ and IL-2 at equivalent concentrations failed to further reduce the percentage of apoptotic cells observed with stimulation with either cytokine alone (data not shown). IL-12 failed to block spontaneous apoptosis in both subsets when used at $10 \mathrm{ng} / \mathrm{ml}$ (Figure 2A,B) and at other concentrations (1, 3, 30 and $100 \mathrm{ng} / \mathrm{ml}$ ) (data not shown). IL-10 was ineffective for $\mathrm{CD}^{+}$cells and weakly effective for $\mathrm{CD}^{+}$cells (Figure
2A,B). IL-4 and IL-7, which utilize the common $\gamma$ receptor chain but not the $\beta$ chain, ${ }^{28}$ were less effective than IL-15 and IL-2, particularly for $\mathrm{CD}^{+}$cells (Figure $3 \mathrm{~A}, \mathrm{~B}$ ).

\section{Potent stimulation of proliferation by IL-15}

Forward versus side scatter profiles revealed substantial induction of large blastic cells in cultures stimulated with IL-15 and to a lesser extent with IL-2 (Figure $2 \mathrm{C}$ ). The potent ability of IL-15 to stimulate proliferation was verified by measuring $\left[{ }^{3} \mathrm{H}\right]$ thymidine incorporation following 3 days stimulation. Proliferation of PBMCs was induced by IL-15 and IL-2 in a dose-dependent manner (Figure 3C). IL-15 was more effective than IL-2 at equivalent concentrations above $1 \mathrm{ng} /$ $\mathrm{ml}$, with differential potency being particularly apparent at $10 \mathrm{ng} / \mathrm{ml}$. Only low levels of $\left[{ }^{3} \mathrm{H}\right]$ thymidine incorporation were detected in IL-12- and IL-10-stimulated cultures, confirming the poor induction by these cytokines of blastic cells distinguished by light scatter properties (Figure 2C), while
A

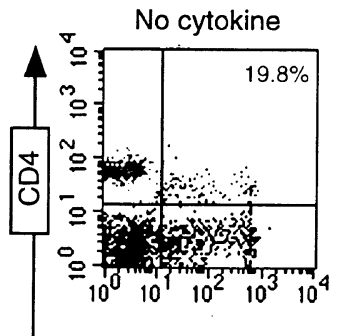

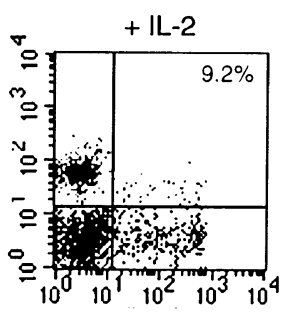
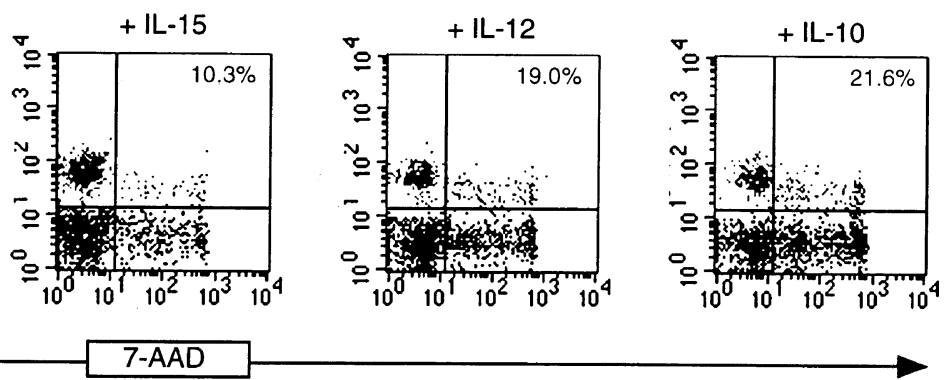

B
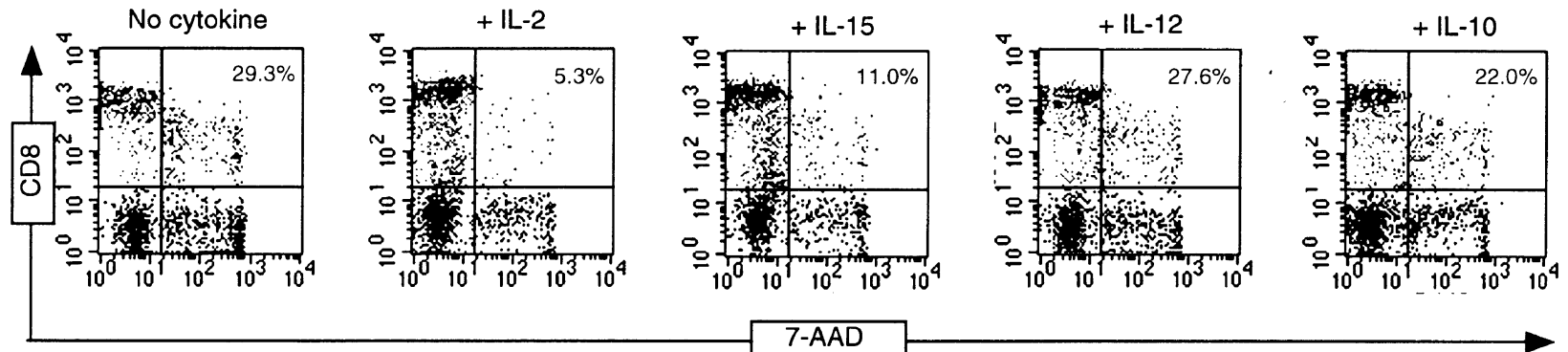

C
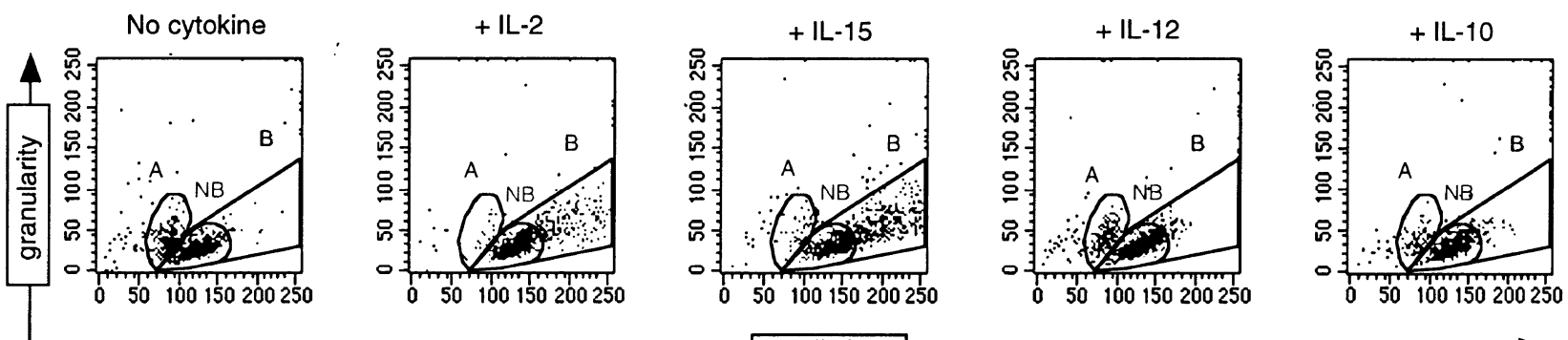

cell size

Figure 2 Differential effects of IL-15 and other exogenous cytokines on spontaneous apoptosis. PBMCs of HIV-infected individuals were incubated for 3 days in the absence of exogenous cytokines or with the addition of IL-2, IL-15, IL-12 or IL-10 at a final concentration of $10 \mathrm{ng} / \mathrm{ml}$, followed by dual-colour immunofluorescence analysis of 7-AAD-staining within the $C D 4^{+}$and $C D 8^{+}$subsets. Shown are representative FACScan profiles indicating the percentage of 7AAD-stained cells within the $\mathrm{CD}^{+}(\mathbf{A})$ and $\mathrm{CD}^{+}(\mathbf{B})$ populations of cultures of PBMCs derived from the same patient. The assessment of apoptosis by 7-AAD incorporation was verified by comparing proportions of apoptotic and living cell populations as distinguished by their distinct light scatter properties. Shown in $\mathbf{C}$ are typical forward versus side scatter profiles of cells gated on the CD8 ${ }^{+}$subset. Apoptotic cells $(\mathbf{A})$, characterized by their small size and high granularity, almost totally comprised the population of 7-AAD-stained $C D 8^{+}$cells shown in (B) whereas cells excluding 7-AAD primarily consisted of living non-blastic (NB) and larger blastic (B) cells 

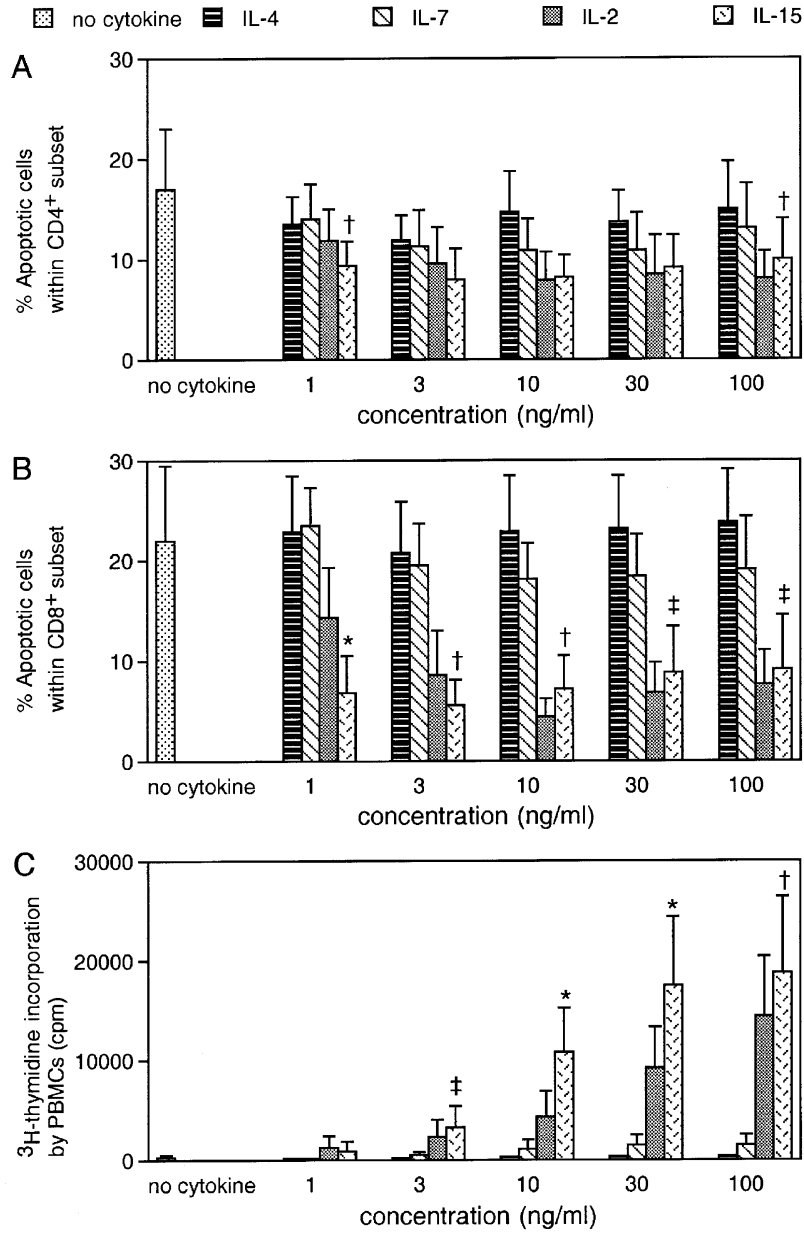

Figure 3 Concentration dependent-effects of exogenous cytokines on spontaneous apoptosis and on proliferation. PBMCs of HIV-infected individuals $(n=15)$ were incubated for 3 days in the absence of exogenous cytokines, or with the addition of the indicated cytokines at final concentrations of $1,3,10,30$ and $100 \mathrm{ng} / \mathrm{ml}$. Dual-colour immunofluorescence analysis was performed to determine the percentages of 7-AAD-stained cells within the $\mathrm{CD}^{+}(\mathbf{A})$ and $\mathrm{CD}^{+}(\mathbf{B})$ subsets. PBMCs of the same patients were also incubated for 3 days as described above and pulsed for the final $16 \mathrm{~h}$ with $1 \mu \mathrm{Ci}$ of $\left[{ }^{3} \mathrm{H}\right]$ thymidine. (C) proliferative responses are expressed in terms of $\left[{ }^{3} \mathrm{H}\right]$ thymidine incorporation (c.p.m.). Statistical significance between responses observed with IL-2 and with IL-15 at a given concentration are as follows: $\$ P<0.02{ }^{*} P<0.01, \pm P<0.05$

proliferative responses induced by IL-4 and IL-7 were similarly weak (Figure 3C).

\section{Greater proliferative responses to IL-15 fail to promote higher cell viability as compared with IL-2-mediated responses}

While IL-15 potently stimulated proliferation in a dosedependent manner (Figure $3 \mathrm{C}$ ), the representation of apoptotic cells within lymphocyte populations of IL-15stimulated cultures was observed not to decrease in a correspondingly dose-dependent manner (Figure 3A,B). This suggested that high cell loss occurs when cells actively proliferate in response to IL-15. This possibility was examined by assessing the total numbers of viable trypan blue dye- excluding cells in unstimulated and cytokine-stimulated PBMC cultures at day 3 . Despite their ability to stimulate proliferation, both IL-15 and IL-2 (10 ng/ml) failed to induce net increases in viable cell numbers during a 3-day culture period as compared with the initial cell count, although viable cell numbers were higher than observed in cultures incubated in the absence of exogenous cytokines $\left(55 \pm 18.10^{4}\right.$ with IL-15 vs $74 \pm 18.10^{4}$ with IL-2 $(P<0.05)$ vs $36 \pm 10.10^{4}$ without cytokine compared to $10^{6}$ cells initially put in culture, $n=17$ ). Furthermore, the total numbers of viable cells in IL-15-stimulated cultures at day 3 were lower than those in IL-2-stimulated cultures. The greater potency of IL-15 to stimulate proliferation, as compared with IL2 , is therefore not reflected by a corresponding higher net increase in viable cell numbers. In contrast to 3-day cultures, the total number of viable cells was higher in day- 1 cultures stimulated with IL-15- than in IL-2-stimulated cultures $\left(110 \pm 16.10^{4}\right.$ with IL-15 vs $94 \pm 10.10^{4}$ with IL-2 $(P<0.05)$ vs $80 \pm 11.10^{4}$ without cytokine), when the representation of blastic cells in these cultures was very small and barely exceeded that observed in cultures without cytokines.

\section{Increased activation and apoptosis-susceptibility of IL-15-stimulated lymphocytes}

The above findings indicated that more cell loss occurs when PBMCs were induced to proliferate by IL-15 than when stimulated with IL-2. This suggested that IL-15 could 'prime' lymphocytes for apoptosis, and that such increased apoptosis-susceptibility could be associated with its potent ability to activate lymphocytes and induce blastogenesis. To initially explore these possibilities, we examined more closely the relative effects of $\mathrm{IL}-15$ and $\mathrm{IL}-2$ on activation and blastogenesis within individual lymphocyte populations, since proliferative responses had been previously measured in the total PBMC population. Both $\mathrm{CD}^{+}$and $\mathrm{CD}^{+}$ lymphocytes which had been stimulated with IL-15 or IL-2 for 3 days were more highly activated than lymphocytes incubated in the absence of exogenous cytokines, as evidenced by the increased representation of cells expressing HLA-DR (Figure 4A) and CD38 (data not shown). Both IL15 and IL-2 induced higher representation of HLA-DR-positive cells and of blastic cells, as defined by their light scatter properties, within the $\mathrm{CD}^{+}$subset than within the $\mathrm{CD} 4^{+}$ subset (Figure $4 \mathrm{~A}, \mathrm{~B}$ ). $\mathrm{CD}^{+}$and $\mathrm{CD}^{+}$populations in IL-15stimulated cultures were more highly activated than those in IL-2-stimulated cultures (Figure 4A), and contained a higher representation of blastic cells (Figure 4B). The greater potency of IL-15, as compared with IL-2, to induce blastogenesis within the $\mathrm{CD}^{+}$and $\mathrm{CD}^{+}$subsets was confirmed by its ability to more highly up-regulate expression of the cell cycle-associated antigens PCNA and Ki-67, and also to induce surface expression of the early activation marker CD69 (data not shown) which strongly correlates with the degree of proliferative activity. ${ }^{29}$

To examine whether lymphocytes proliferating in response to IL-15 were more apoptosis-susceptible than lymphocytes induced to proliferate by IL-2, PBMCs preincubated without exogenous cytokines, or pre-activated with either IL-2 or IL-15 for 3 days, were subsequently washed in medium and incubated for a further period of 3 

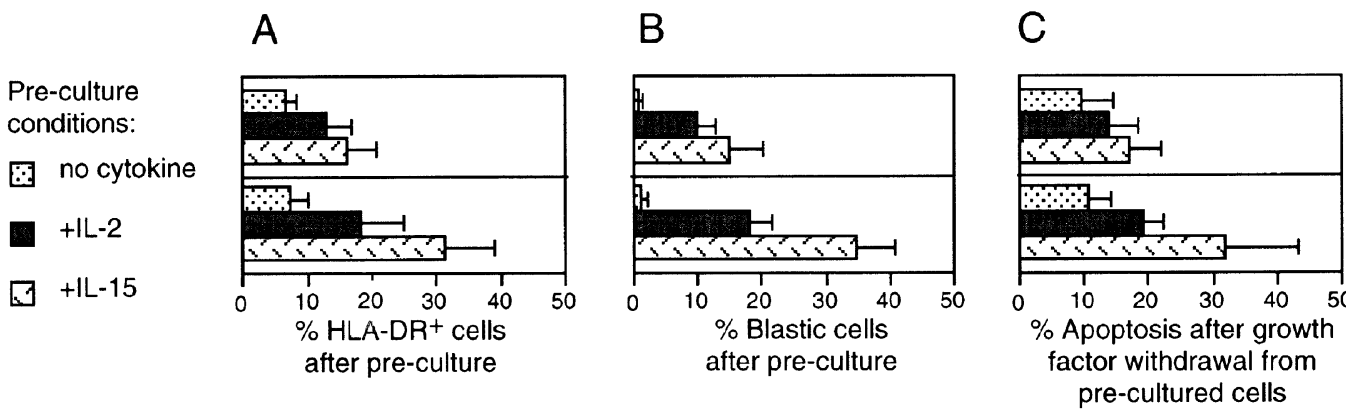

Figure 4 Effects of IL-15 and IL-2 on lymphocyte activation and blastogenesis, and susceptibility of cytokine-pre-activated lymphocytes to apoptosis. PBMCs of HIV-infected individuals ( $n=14)$ were pre-incubated for 3 days in the absence of exogenous cytokines or with the addition of IL-2 or IL-15 (10 ng/ml). In (A) the percentages of HLA-DR-positive cells within the $\mathrm{CD}^{+}$and $\mathrm{CD}^{+}$subsets following the pre-incubation period were determined by dual-colour immunofluorescence analysis. Shown in (B) are the percentages of blastic cells within each subset, as determined by their distinct scatter patterns as shown in Figure $2 \mathrm{C}$. Following preincubation without exogenous cytokines or with IL-2 or IL-15, cells were washed twice in medium and incubated for a further period of 3 days in the absence of exogenous cytokines, at the end of which the percentages of apoptotic 7-AAD-stained cells within the $\mathrm{CD}^{+}$and $\mathrm{CD} 8^{+}$subsets were determined (shown in C)

days in the absence of exogenous cytokines at the end of which the percentages of apoptotic cells within lymphocyte populations were assessed by 7-AAD incorporation. Higher percentages of 7-AAD-stained apoptotic cells were found in lymphocyte populations which had been previously activated with either IL-15 or IL-2 than in populations which had not been pre-activated with cytokines, and IL-15pre-activated lymphocytes demonstrated a higher propensity to undergo apoptosis following growth factor withdrawal than lymphocytes pre-activated with IL-2 (Figure 4C). It therefore appears that IL-15 stimulation can render lymphocytes more susceptible to apoptosis than IL-2 stimulation, and that such increased apoptosis-susceptibility appears to be associated with the greater ability of IL15 to activate lymphocytes and induce blastogenesis.

\section{IL-15 is a potent survival factor for lymphocytes. Influence of etoposide}

Although total viable cell numbers in IL-15-stimulated PBMC cultures were lower than those in IL-2-stimulated cultures at day 3 , the converse was observed at day 1 when little proliferation was detected in response to either cytokine, as discussed above. Furthermore, IL-15 was more effective than $\mathrm{IL}-2$ in reducing the representation of apoptotic cells at day 3 when used at low concentrations at which only weak proliferative responses were induced by these cytokines (Figures $3 A, B, C$ ). These observations together suggested that IL-15 could be more effective than IL-2 in enhancing lymphocyte survival per se. The possibility that IL-15 could be more potent than IL-2 as a lymphocyte survival factor was confirmed by the abilities of IL-15 and IL-2 to decrease the pool of apoptotic cells within lymphocyte populations in 3-day PBMC cultures treated with etoposide. This topoisomerase II inhibitor causes a block in the S/G2 phase of the cell cycle and has been used to dissociate cytokine-induced survival from proliferation. ${ }^{30}$ As shown in Figure 5 , the effectiveness of etoposide in blocking $\mathrm{CD}^{+}$and $\mathrm{CD}^{+}$lymphocyte proliferation induced by IL-2 and IL-15 was clearly evident by the absence of large blastic cells as visualized on forward versus side scatter profiles. IL-15 was markedly more effective than
$\mathrm{IL}-2$, when used at the equivalent concentration of $10 \mathrm{ng} / \mathrm{ml}$, in reducing the percentage of apoptotic cells within the CD4 ${ }^{+}$ subset, and particularly within the $\mathrm{CD}^{+}$subset, of etoposidetreated cultures (Figure 5).

\section{Greater survival potency of IL-15 is associated with higher bcl-2 up-regulation}

It is well-established that the bcl-2 molecule plays a crucial role in regulating lymphocyte survival. ${ }^{31-33}$ Down-regulated expression of bcl-2 has been observed in lymphocytes of HIVinfected individuals undergoing spontaneous apoptosis ${ }^{22}$ and the ability of exogenous IL-2 to inhibit such apoptosis is associated with up-regulation of bcl-2 expression. ${ }^{19} \mathrm{We}$ therefore investigated whether the greater enhancement of $\mathrm{CD}^{+}$and $\mathrm{CD}^{+}$lymphocyte survival induced by IL-15, as compared with IL-2, was associated with higher up-regulation of bcl-2 expression. This was assessed by examining changes in mean fluorescence intensity (MFI) of intracellular $\mathrm{Bcl}-2$ staining, a method commonly used for heterogeneous cell populations. ${ }^{12,22,23}$ As shown in Figure $6 \mathrm{~A}$, IL-15 stimulation led to increases in bcl-2 MFI within the gated $\mathrm{CD}^{+}$and $\mathrm{CD}^{+}$populations of etoposide-treated cultures, which were markedly higher than increases observed with IL2 stimulation. Since etoposide itself further augmented apoptosis (Figure 5) leading to decreased bcl-2 expression, we confirmed the ability of IL-15 to more highly upregulate bcl2 expression than IL-2 in cultures incubated without etoposide: MFI within CD4+ subset $135 \pm 38$ with IL-15 vs $122 \pm 36$ with IL-2 $(P<0.05)$ vs $91 \pm 25$ without cytokine, and MFI within CD8+ subset $165 \pm 44$ with IL-15 vs $138 \pm 44$ with IL-2 $(P<0.05)$ vs $76 \pm 26$ without cytokine. The relative reduction in levels of apoptosis within the $\mathrm{CD}^{+}$and $\mathrm{CD} 8^{+}$subsets in etoposide-treated cultures stimulated with IL-15 and IL-2 was found to correlate strongly with the relative increases in bcl-2 $\mathrm{MFI}$ in the gated living cell populations of each subset (Figure $6 \mathrm{~B})$. The correlation factors were very similar for IL-15 and IL2 for a given subset, and were stronger for the $\mathrm{CD}^{+}$subset. The increases in bcl- 2 expression in living $\mathrm{CD}^{+}$cells, and particularly in living $\mathrm{CD}^{+}$cells, were markedly higher in IL-15stimulated cultures than in IL-2-stimulated cultures, support- 


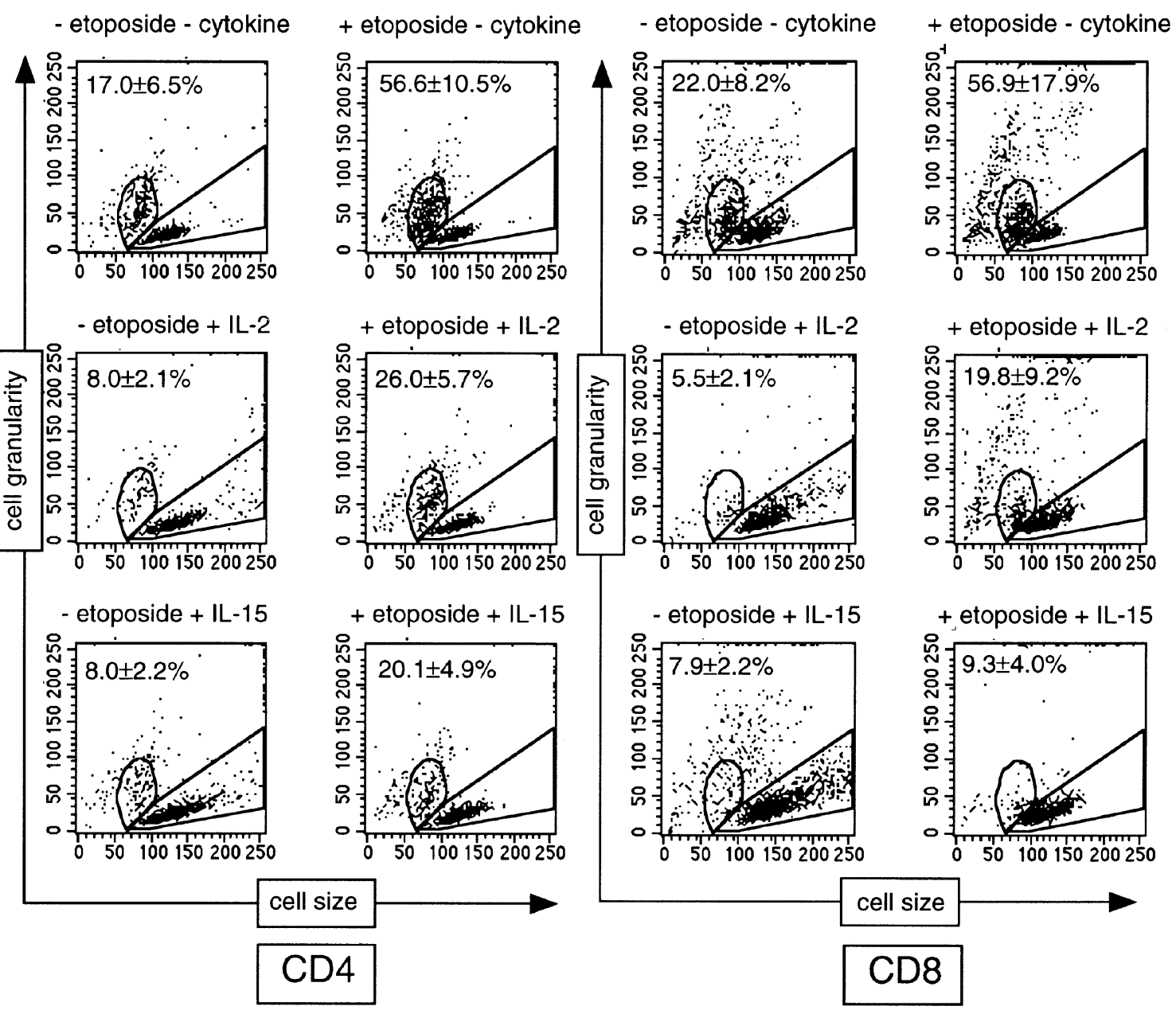

Figure 5 Relative effects of IL-15 and IL-2 on lymphocyte survival. PBMCs of HIV-infected individuals $(n=14)$ were incubated for 3 days in the absence or presence of etoposide $(20 \mu \mathrm{M})$, either without exogenous cytokines or with the addition of IL-2 or IL-15 $(10 \mathrm{ng} / \mathrm{ml})$. Cells were stained with either anti-CD4 or antiCD8 mAbs. Shown are forward versus side scatter profiles gated on $\mathrm{CD} 4^{+}$and $\mathrm{CD} 8^{+}$cells of cultures of PBMCs derived from the same patient. The cell populations circled correspond to apoptotic cells (low FSC) or living cells (higher FSC). The percentages shown on each panel correspond to the representation of apoptotic cells (mean \pm S.D.) within CD4 or CD8 T cell subsets

ing the notion that IL-15 can act as a potent lymphocyte survival factor.

\section{Discussion}

The present study indicates that exogenous IL-15 can exert a beneficial influence on lymphocytes of HIV-infected individuals by two fundamental mechanisms. Firstly, IL-15 can act as a potent survival factor in the prevention of spontaneous lymphocyte apoptosis. Secondly, IL-15 can expand the pool of viable lymphocytes by its potent ability to induce proliferation. The abilities of exogenous IL-15 to strongly promote both survival and proliferation of lymphocytes of HIVinfected individuals is of critical importance, given the detrimental role which alterations in the profile of cytokine production and cytokine deprivation, and associated cell loss play in HIV pathogenesis. However, the present study also reveals two disadvantages of $\mathrm{IL}-15$ in regard to regulating viability and number of lymphocytes of HIV-infected individuals. One concern relates to its inability to inhibit
CD95-induced apoptosis, which in addition to cytokine deprivation, is believed to be major contributory factor to lymphocyte depletion in HIV-infected individuals. The second disadvantage is the increased lymphocyte activation state and associated increased apoptosis-susceptibility arising from the potent ability of IL-15 to induce proliferation.

The greater survival-enhancing effect of $\mathrm{IL}-15$, as compared with that of IL-2 at an equivalent concentration, is highly likely to be associated with quantitative differences in the strength of the transduced signal, and not with qualitative differences in the signaling pathways triggered by these cytokines. Both IL-15 and IL-2 signal through the $\beta$ and $\gamma$ receptor chains, which are coupled to the bcl-2 survival pathway, and also growth regulatory pathways involving c-myc and fos/jun. 4,34,35 The $\alpha$ receptor chains, specific to each cytokine, do not appear to play crucial roles in signal transduction but determine binding affinity. ${ }^{28,36}$ The greater ability of $\mathrm{IL}-15$ to enhance survival, and also to induce proliferation, is consistent with studies indicating the greater binding affinity of the IL-15 
A
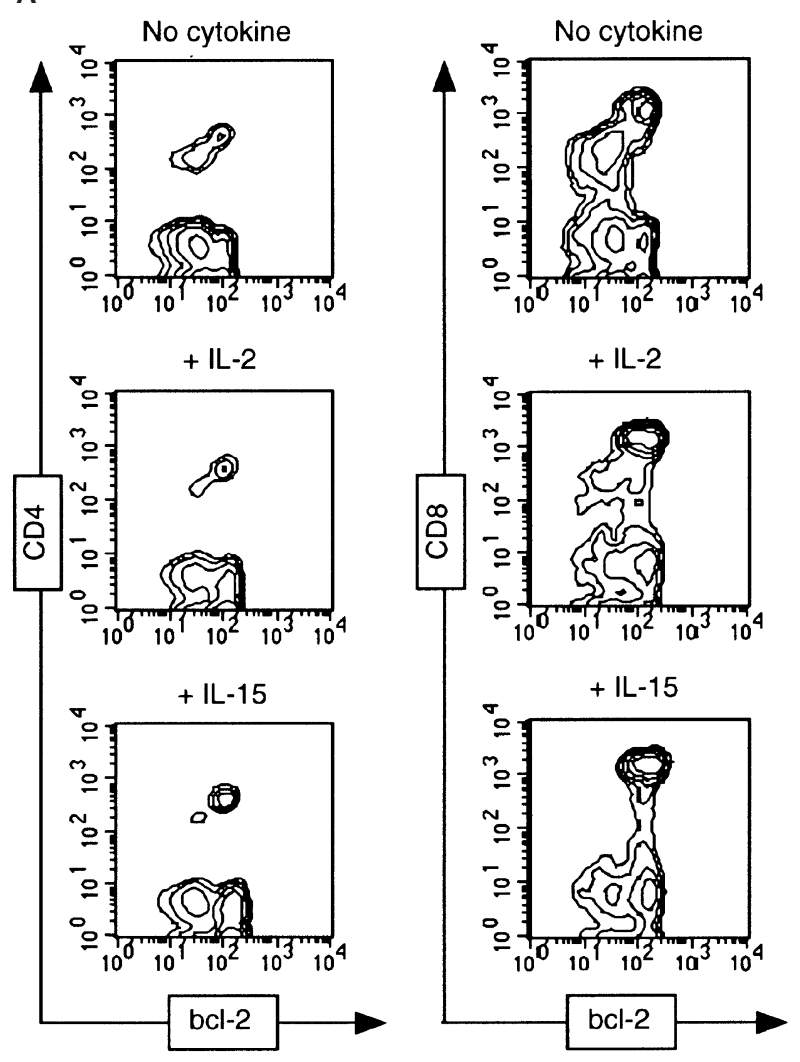

B
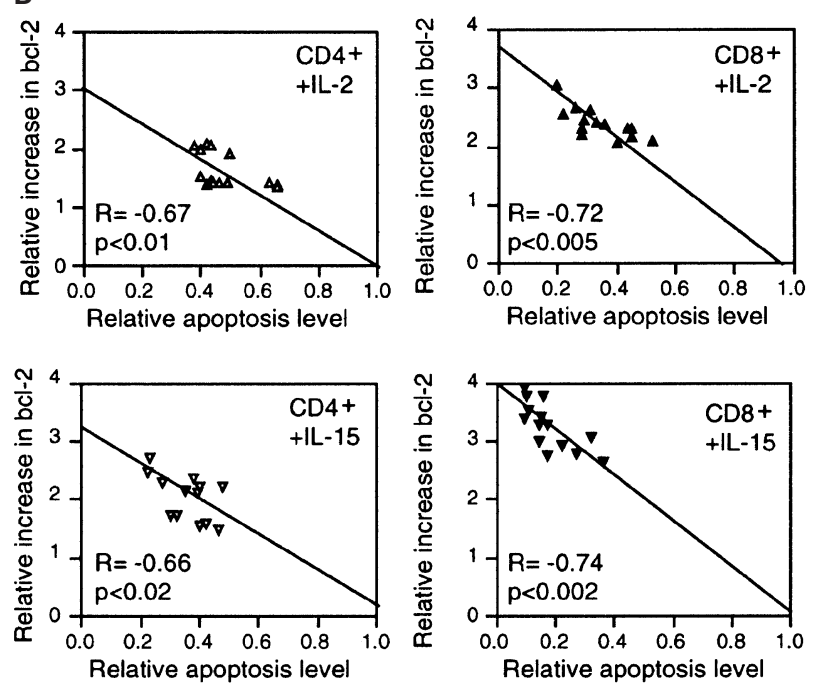

Figure 6 Relative effects of IL-15 and IL-2 on up-regulating bcl-2 expression and correlation with reduced levels of apoptosis. PBMCs of the same group of individuals as described in Figure 5 were incubated for 3 days in the presence of etoposide $(20 \mu \mathrm{M})$, either without exogenous cytokines or with the addition of IL-2 or IL-15 $(10 \mathrm{ng} / \mathrm{ml})$. Cells were stained with 7-AAD and either anti-CD4 or anti-CD8 mAbs, permeabilized and stained intracellularly with anti-bcl-2 mAbs. Shown in (A) are FACScan profiles of bcl-2 expression in the $\mathrm{CD} 4^{+}$and $\mathrm{CD}^{+}$subsets of the same patient. Mean MFI values of bcl-2 staining within gated $\mathrm{CD} 4^{+}$and $\mathrm{CD} 8^{+}$populations of the patient group are the following $57 \pm 16$ without cytokine, $93 \pm 24$ with IL-2 $(P<0.01)$ and $112 \pm 22$ with IL-15 $(P<0.01)$ for gated $\mathrm{CD} 4^{+}$cells, $40 \pm 11$ without cytokine, $93 \pm 29$ with IL-2 $(P<0.01)$ and $127 \pm 28$ with IL-15 $(P<0.01)$ for gated CD8 ${ }^{+}$cells. In $(B)$ the relative apoptosis level observed within a given subset in cultures stimulated receptor $\alpha$ chain for IL-15, as compared with that of the IL-2 receptor $\alpha$ chain for IL-2. ${ }^{37}$ The stronger ability of both IL-15 and IL-2 to promote survival and proliferation of the $\mathrm{CD}^{+}$ subset, as compared with the $\mathrm{CD}^{+}$subset, is likely to be associated with the higher surface expression of the $\beta$ chain on $\mathrm{CD}^{+}$cells, ${ }^{38}$ since we have observed little difference between the subsets in their ex vivo expression levels of the $\gamma$ chain. ${ }^{39}$ Furthermore, proliferative responses to IL-15 are more efficiently blocked by mAbs directed against the $\beta$ chain than by mAbs against the $\gamma$ chain. ${ }^{40}$ It should be noted that the correlations between the reduced levels of apoptosis induced by IL-15 and by IL-2 and the up-regulated expression of bcl-2 were less strong in the $\mathrm{CD}^{+}$subset, as compared to the $\mathrm{CD}^{+}$subset. This suggests the involvement of other factors in addition to bcl2 in enhancing survival of $\mathrm{CD}^{+}$lymphocytes, for example bcl- $x_{\mathrm{L}}$, which is up-regulated by $\gamma$ chain signaling. ${ }^{30}$

Since spontaneous apoptosis involves decreased bcl-2 expression, ${ }^{19,22}$ the protective effect of IL-15 could be explained in terms of promoting a survival pathway whose down-modulation is associated with this particular mode of death. By the same token, findings that signaling through the CD95 molecule does not directly down-regulate bcl-2, and that the bcl-2 survival pathway poorly protects lymphocytes from death triggered by these molecules, ${ }^{41,42}$ could simplistically explain the effectiveness of IL-15 (and of IL2) against death triggered by these molecules. Although the bcl-2 and CD95 molecules apparently regulate distinct, independent pathways in lymphocytes, bcl-2 is able to block apoptosis induced in mouse liver by anti-CD95 antibodies. ${ }^{43}$ This could explain the recently reported greater ability of IL15 fusion proteins, as compared with those of $\mathrm{IL}-2$ at equivalent doses in vivo, to inhibit lethal CD95-induced hepatic failure. ${ }^{20}$ Up-regulation of bcl-2 expression apparently protects cells from HIV-protease-mediated death ${ }^{44}$ and also from apoptosis induced by CD4 cross-linking. ${ }^{45}$ While further investigation is required, the high increases in bcl-2 expression associated with IL-15-mediated survival could have important implications in protecting lymphocytes from apoptosis in HIV infection involving the actions of various viral proteins, as well as preventing death from occurring by cytokine deprivation.

Our observations with lymphocytes of HIV-infected individuals contrast with those of a recent study which found IL-15 to inhibit CD95-induced death of T cells derived from uninfected individuals which had been transiently preactivated by mitogens in vitro. ${ }^{20}$ Given that lymphocytes of HIV-infected individuals have been chronically activated in vivo, the differences between the observations could

with IL-2 and with IL-15 were plotted against the relative increases in bcl-2 expression in the living cell population of each subset. The relative apoptosis level within each subset in the presence of a given cytokine is defined as the percentage of 7-AAD-stained cells in cultures incubated with the cytokine expressed as a ratio of the percentage of 7-AAD-stained cells in cultures incubated in the absence of exogenous cytokines. The relative increase in bcl2 expression within the gated living cell population of each subset is defined as the MFI of anti-bcl-2 mAb staining detected in the presence of the cytokine expressed as a ratio of the MFI detected in the absence of exogenous cytokines. Correlations were determined using the Spearman regression analysis 
possibly lie in the quantitative and/or qualitative differences in the nature of lymphocyte activation, and raises the possibility that chronic activation in vivo could modify the ability of cytokines to influence susceptibility to CD95induced death. Although a mechanism for the protective effect of IL-15 against such death was not shown in the earlier study, it could possibly involve bcl- $x_{L}$ which, when ectopically expressed, prevents loss of mitochondrial membrane potential associated with CD95-induced protease activation. ${ }^{46}$ Although up-regulated expression of bcl$\mathrm{X}_{\mathrm{L}}$ in preactivated $\mathrm{T}$ lymphoblasts derived from uninfected donors has been observed in response to IL-15 and IL$2,^{30,47}$ the question as to whether the modest level of cytokine-induced $\mathrm{bcl}-\mathrm{x}_{\mathrm{L}}$ would be sufficient to counter the CD95 death signal is challenged by recent findings. ${ }^{48}$

While the potent ability of exogenous IL-15 to enhance survival of lymphocytes of HIV-infected individuals is clearly advantageous, the present study indicates that its likewise potent ability to induce proliferation can be both beneficial in expanding lymphocyte populations, and also detrimental by virtue of increasing the lymphocyte activation state. The negative effect associated with increased blastogenesis was apparent by the less effective ability of IL-15 to reduce the representation of apoptotic cells in the absence of etoposide as compared to in the presence of etoposide (Figure 5). Furthermore, although IL-15 was more potent than IL-2 at an equivalent concentration in both enhancing survival and in stimulating proliferation, IL-15 failed to induce increases in the representation and total number of viable cells which were higher than those induced by IL-2. Such failure appears to be attributable to greater cell loss occurring when cells are actively proliferating in response to IL-15 than to IL-2, and associated with the ability of IL-15 to more highly activate lymphocytes and increase their apoptosis-susceptibility. In other words, it appears that cell loss associated with the increased activation state counter-balances increases in lymphocyte viability promoted by cytokineinduced survival and proliferation to a greater extent in the case of IL-15 than with IL-2. The mechanisms underlying the increased apoptosis-susceptibility of activated proliferating lymphocytes are as yet unclear. However since IL-15 was more effective than IL-2 in promoting bcl-2 up-regulation both in the presence and absence of etoposide, it would seem that cell loss associated with IL-15 stimulation does not involve a poorer ability of IL-15 to upregulate bcl-2 under conditions where lymphocytes are proliferating. While the increased apoptosis-susceptibility of activated, proliferating lymphocytes plays a crucial, homeostatic role in controlling expansion of lymphocyte populations, ${ }^{32,49}$ the detrimental effect of increased activation associated with cytokine stimulation should be closely considered particularly in the case of HIV infection where the immune system is already chronically activated.

The findings of the present study highlight the need to closely weigh the positive effects of exogenous cytokines on survival and on proliferation against the disadvantages of increased activation and associated apoptosis-susceptibility when assessing their immunotherapeutic potential particularly in treating chronic viral infections such as that of HIV. The proliferative advantage of IL-15 may need to be more strongly compromised than that of IL-2 in order to minimize cell loss. Although caution must be obviously exercised in interpreting relative effects of cytokines observed in vitro, the study raises the possibility that the required dosage of exogenous IL-15 in vivo may be considerably less than that of IL-2 to promote comparable maintenance and expansion of lymphocyte populations in HIV-infected individuals. In addition, the required dosage of $\mathrm{IL}-15$ in vivo could be possibly less than that of IL-2 in view that IL-15 is endogenously produced by a wide variety of tissues, in contrast to IL-2 whose production is primarily restricted to $\mathrm{T}$ cells, ${ }^{1,2}$ and that IL-15 can apparently stimulate IL-2 secretion by $\mathrm{T}$ lymphoblasts whereas IL-2 is unable to induce IL15 secretion. ${ }^{50}$ Lower dosages would be of obvious benefit in reducing toxic side-effects and augmentation of HIV replication. In addition, the observed potency of IL-15 in stimulating expansion of $\mathrm{CD}^{+}$lymphocytes should also be considered in assessing dosage in regard to risks associated with augmented virus replication and benefits of enhancing host-mediated anti-viral activities.

\section{Materials and Methods}

\section{Human blood samples}

Peripheral blood samples were obtained from 58 HIV-1 infected patients at the Service for Infectious and Tropical Diseases (Pr René Roué), Bégin Military Hospital, St. Mandé, France. None of the patients studied were receiving treatment with IL-2 or HIV protease inhibitors. Forty-six patients received therapy consisting of the combination of two HIV reverse transcriptase inhibitors. Ex vivo CD4 percentages ranged as follows: CD $4>28 \%, n=2 ; 13 \%<C D 4 \leqslant 28 \%$, $n=24 ; C D 4 \leqslant 13 \%, n=32$, according to the revised HIV infection classification of the Centers of Disease Control (Atlanta, GA, USA). ${ }^{21}$

\section{PBMC isolation and stimulation}

PBMCs were freshly isolated from heparinized blood by centrifugation on Ficoll-Hypaque (Pharmacia, Uppsala, Sweden) and incubated for $1-3$ days at $10^{6}$ cells $/ \mathrm{ml}$ in complete medium, as previously described. ${ }^{15}$ Anti-CD95 mAbs (clone UB2) (Immunotech, Marseille, France) were immobilized to wells of 24-well plates by incubating wells with $100 \mu \mathrm{l}$ of $100 \mu \mathrm{g} / \mathrm{ml} \mathrm{mAbs}$ for $1 \mathrm{~h}$, following by rinsing with PBS. Recombinant human IL-2, IL-4, IL-7, IL-10, IL-12 and IL-15 (R\&D Systems, Abingdon, UK) were used at concentrations indicated in the text. In specific experiments, etoposide (Sigma) was added at a pretitrated optimal final concentration of $20 \mu \mathrm{M}$.

\section{Proliferation assays}

PBMCs were resuspended at an initial concentration of $2 \times 10^{5}$ cells/ $200 \mu \mathrm{l}$ per well in 96-well flat bottom plates and incubated for 3 days in the absence or presence of exogenous cytokines. Samples were pulsed for the final $16 \mathrm{~h}$ with $1 \mu \mathrm{Ci} /$ well of $\left[{ }^{3} \mathrm{H}\right]$ thymidine (Amersham, Bucks., UK) and harvested on to glass fibre filters. Radioactivity was measured by liquid scintillation counting.

\section{Monoclonal antibodies}

The mouse mAbs specific for human surface antigens included: FITCconjugated anti-CD69 ( $\operatorname{lgG}_{1}$, clone L78); anti-CD38 (IgG 1 , clone HB-7) 
and anti-HLA-DR ( $\operatorname{lgG}_{2 a}$, clone L243) conjugated to phycoerythrin (PE); anti-CD4 ( $\lg G_{1}$, clone SK3) and anti-CD8 ( $\operatorname{lgG}_{1}$, clone SK1) conjugated to either FITC, PE or PerCP (Becton Dickinson, San Jose, $\mathrm{CA}$, USA). FITC-conjugated mAbs against bcl-2 ( $\operatorname{lgG}_{1}$, clone 124) (Dako, Glostrup, Denmark), proliferating cell nuclear antigen (PCNA) (IgG $\mathrm{I}_{2 \mathrm{a}}$, clone PC10) (Caltag, Burlingame, CA, USA) and Ki-67 (IgG 1 , clone MIB-1) (Immunotech) were used for intracellular staining. Appropriately conjugated isotype-matched controls (mouse $\operatorname{lgG}_{1}$ and $\lg _{2 a}$ ) were obtained from Dako.

\section{Cell staining and FACScan analysis}

$5 \times 10^{5}$ PBMCs, either freshly isolated or following culture, were washed in PBS containing $1 \%$ BSA and $0.1 \%$ sodium azide (PBS$\mathrm{BSA}-\mathrm{NaN}_{3}$ ) and incubated for $20 \mathrm{~min}$ at $4{ }^{\circ} \mathrm{C}$ with surface antigenspecific mAbs described above (1:50 dilution). Stained cells were washed and fixed in $1 \%$ paraformaldehyde for $20 \mathrm{~min}$ at $4^{\circ} \mathrm{C}$. Subsequent intracellular staining was performed as previously described. ${ }^{22}$ Briefly, fixed cells were washed, permeabilized in PBSBSA-NaN $\mathrm{N}_{3}$ containing $0.05 \%$ saponin (w/v) (Sigma) and stained with mAbs against bcl-2, PCNA or Ki-67 (1:50 dilution). Stained cells were washed, fixed and applied to a FACScan flow cytometer (Becton Dickinson). For each sample, 10000 viable lymphocytes were gated following size and granularity parameters and analyzed with Cell Quest software (Becton Dickinson).

\section{Analysis of apoptotic cells}

Quantification of apoptotic cells in short-term cultures was performed by staining with 7-amino-actinomycin $D$ (7-AAD) (Sigma), the degree of fluorescence of which closely corresponds with alterations in membrane permeability and the stage of apoptosis. ${ }^{23,24}$ Cultured cells were incubated with mAbs specific for surface antigens together with 7-AAD $(20 \mu \mathrm{g} / \mathrm{ml})$ for $20 \mathrm{~min}$ at $4^{\circ} \mathrm{C}$. Subsequent washes and cell fixation were carried out with the inclusion of nonfluorescent actinomycin $D(20 \mu \mathrm{g} / \mathrm{ml})$ to prevent further $7-A A D$ staining within apoptotic cells and non-specific labeling of living cells. ${ }^{22}$ Spectral properties of 7-AAD allowed detection of apoptotic cells by fluorescence emission in the red channel FL-3, and simultaneous labeling of surface antigens (FL-1 and FL-2).

\section{Acknowledgements}

The authors thank Prof. René Roué and Dr. Thierry Debord of the Service of Infectious and Tropical Diseases, Bégin Military Hospital, St. Mandé, France for their collaboration in the clinical aspect of this study. Thanks are also extended to members of the Viral Oncology Unit, for discussions. The authors acknowledge Prof. Luc Montagnier for his support during this study. This work was supported by grants from the Agence Nationale de Recherche sur le SIDA (ANRS), the Fondation pour la Recherche Medicale (FRM) (Sidaction), the CNRS, the Pasteur Institute, and the European Community (EEC) contracts NO BMH4-CT 97-2055 and ERB-IC15-CT97-O901). H Naora was supported by a fellowship from FRM.

\section{References}

1. Grabstein KH, Eisenman J, Shanebeck K, Rauch C, Srinivasan S, Fung V, Beers C, Richardson J, Schoenborn MA, Ahdieh M, Johnson L, Alderson MR, Watson JD, Anderson DM and Giri JG (1994) Cloning of a T cell growth factor that interacts with the $\beta$ chain of the interleukin-2 receptor. Science 264: 965-968
2. Bamford BN, Grant AJ, Burton JD, Peters C, Kurys G, Goldman CK, Brennan J, Roessler E and Waldmann TA (1994) The interleukin (IL) 2 receptor $\beta$ chain is shared by $\mathrm{IL}-2$ and a cytokine, provisionally designated IL-T, that stimulates T-cell proliferation and the induction of lymphokine-activated killer cells. Proc. Natl. Acad. Sci. USA 91: 49404944

3. Carson WE, Giri JG, Lindemann MJ, Linett ML, Ahdieh M, Paxton R, Anderson D, Eisenmann J, Grabstein K and Caligiuri MA (1994) Interleukin (IL) 15 is a novel cytokine that activates human natural killer cells via components of the IL-2 receptor. J. Exp. Med. 180: 1395-1403

4. Giri JG, Adhieh M, Eisenmann J, Shanebeck K, Grabstein K, Kumaki S, Namen A, Park LS, Cosman D and Anderson D (1994) Utilization of the $\beta$ and $\gamma$ chains of the IL-2 receptor by the novel cytokine IL-15. EMBO J. 13: 2822-2830

5. Kovacs JA, Baseler M, Dewar RJ, Vogel S, Davey RT, Falloon J, Polis MA, Walker RE, Stevens R, Salzman NP, Metcalf JA, Masur H and Lane HC (1995) Increases in CD4 T lymphocytes with intermittent courses of interleukin-2 in patients with human immunodeficiency virus infection. N. Eng. J. Med. 332: $567-575$

6. Lucey DR, Pinto LA, Bethke FR, RusnakJ, Melcher GP, HashemiFN, Landay AL, Kessler HA, Paxton RJ, Grabstein Kand Shearer GM (1997) In vitro immunologic and virologic effects of interleukin 15 on peripheral blood mononuclear cells from normal donors and human immunodeficiency virus type 1 -infected patients. Clin. Diagn. Lab. Immunol. 4: 43-48

7. Chehimi J, Marshall JD, Salvucci O, Frank I, Chehimi S, Kawecki S, Bacheller D, Rifat S and Chouaib S (1997) IL-15 enhances functions during HIV infection. J. Immunol. 158: 5978-5987

8. Kanai T, Thomas EK, Yasutomi Y and Letvin NL (1996) IL-15 stimulates the expansion of AIDS virus-specific CTL. J. Immunol. 157: 3681-3687

9. Munger W, Quinn DeJoy S, Jeyaseelan R, Torley LW, Grabstein KH, Eisenmann J, Paxton R, Cox T, Wick MM and Kerwar SS (1995) Studies evaluating the antitumor activity and toxicity of interleukin-15, a new $\mathrm{T}$ cell growth factor: Comparison with interleukin-2. Cell Immunol. 165: 289-293

10. Gougeon M-L (1995) Does apoptosis contribute to CD4 T cell depletion in human immunodeficiency virus infection? Cell Death Differ. 2: 1-8

11. Clerici M, Sarin A, Henkart PA and Shearer GM (1997) Apoptotic cell death and cytokine dysregulation in human immunodeficiency virus infection: pivotal factors in disease progression. Cell Death Differ. 4: $699-706$

12. Ledru E, Lecoeur H, Garcia S, Debord T and Gougeon M-L (1998) Differential susceptibility to activation-induced apoptosis among peripheral Th1 subsets: Correlation with bcl-2 expression and consequences for AIDS pathogenesis. J. Immunol. 160: 3194-3206

13. Groux H, Torpier G, Monte D, Mouton Y, Capron A and Ameisen JC (1992) Activation-induced death by apoptosis in $\mathrm{CD}^{+} \mathrm{T}$ cells from human immunodeficiency virus-infected asymptomatic individuals. J. Exp. Med. 175: $331-340$

14. Katsikis PD, Wunderlich ES, Smith CA, Herzenberg LA and Herzenberg LA (1995) Fas antigen stimulation induces marked apoptosis of T lymphocytes in human immunodeficiency virus-infected individuals. J. Exp. Med. 181: 20292036

15. Gougeon M-L, Lecoeur H, Dulioust A, Enouf M-G, Crouvoisier M, Goujard C, Debord T and Montagnier L (1996) Programmed cell death in peripheral lymphocytes from HIV-infected persons. Increased susceptibility to apoptosis of CD4 and CD8 T cells correlates with lymphocyte activation and with disease progression. J. Immunol. 156: $3509-3520$

16. Estaquier J, Idziorek T, Zou E, Emilie D, Farber C-M, Bourez J-Mand Ameisen JC (1995) T helper type 1/T helper type 2 cytokines and T cell death: preventive effect of interleukin 12 on activation-induced and CD95 (Fas/APO-1)-mediated apoptosis of $\mathrm{CD} 4^{+} \mathrm{T}$ cells from human immunodeficiency virus-infected persons. J. Exp. Med. 182: 1759-1767

17. Clerici M, Sarin A, Berzofsky JA, Landay AL, Kessler HA, Hashemi F, Hendrix CW, Blatt SP, Rusnak J, Dolan MJ, Coffman RL, Henkart PA and Shearer GM (1996) Antigen-stimulated apoptotic T-cell death in HIV infection is selective for $\mathrm{CD4}^{+} \mathrm{T}$ cells, modulated by cytokines and effected by lymphotoxin. AIDS 10 : 603-611

18. Gougeon M-L, Garcia S, Heeney J, Tschopp R, Lecoeur H, Guetard D, Rame V, Dauguet $C$ and Montagnier L (1993) Programmed cell death in AIDS-related HIV and SIV infections. AIDS. Res. Hum. Retroviruses 9: 553-563 
19. Adachi Y, Oyaizu N, Than S, McCloskey TW and Pahwa S (1996) IL-2 rescues in vitro lymphocyte apoptosis in patients with HIV infection. Correlation with its ability to block culture-induced down-modulation of Bcl-2. J. Immunol. 157: 4184-4193

20. Bulfone-Paus S, Ungureanu D, Pohl T, Lindner G, Paus R, Ruckert R, Krause H and Kunzendorf U (1997) Interleukin-15 protects from lethal apoptosis in vivo. Nature Med. 3: 1124

21. Centers for Disease Control (1992) 1993 revised classification system for HIV infection and expanded surveillance case definition for AIDS among adolescents and adults. Morb. Mort. Wkly. Rep. 41: 1-19

22. Boudet F, Lecoeur Hand Gougeon M-L (1996) Apoptosis associated with ex vivo down-regulation of bcl-2 and up-regulation of Fas in potential cytotoxic CD8 ${ }^{+} \mathrm{T}$ lymphocytes during HIV infection. J. Immunol. 156: 2282-2293

23. Schmid I, Uittenbogaart CH, Keld B and Giorgi JV (1994) A rapid method for measuring apoptosis and dual-colour immunofluorescence by single laser flow cytometry. J. Immuno. Methods 170: 145-157

24. Lecoeur H, Ledru E, Prevost M-C and Gougeon M-L (1997) Strategies for phenotyping apoptotic peripheral human lymphocytes comparing ISNT, annexin-V and 7-AAD cytofluorometric staining methods. J. Immuno. Methods 209: $111-118$

25. Gougeon M-L, Lecoeur H, Boudet F, Marzabal S, Bouiller S, Roue R, Nagata S and Heeney $J$ (1997) Lack of chronic immune activation in HIV-infected chimpanzee correlates with the resistance of T cells to Fas/Apo-1 (CD95)induced apoptosis and preservation of a Thelper 1 phenotype. J. Immunol. 158: 2964-2976

26. Katsikis PD, Garcia-Ojeda ME, Wunderlich ES, Smith CA, Yagita H, Okumura K Kayagaki N, Alderson M, Herzenberg LA and Herzenberg LA (1996) Activationinduced peripheral blood T cell apoptosis is Fas-independent in HIV-infected individuals. Int. Immunol. 8: 1311-1317

27. Estaquier J, Tanaka M, Suda T, Nagata S, Golstein P and Ameisen JC (1996) CD95-mediated apoptosis of $\mathrm{CD}^{+}$and $\mathrm{CD}^{+} \mathrm{T}$ cells from human immunodeficiency virus-infected persons: differential in vitro preventive effect of cytokines and protease antagonists. Blood 87: 4959-4966

28. Sugamura K, Asao H, Kondo M, Tanaka N, Ishii N, Ohbo K, Nakamura M and Takeshita T (1996) The interleukin-2 receptor $\gamma$ chain: its role in the multiple cytokine receptor complexes and T cell development in XSCID. Annu. Rev. Immunol. 14: 179-205

29. Simms PE and Ellis TM (1996) Utility of flow cytometric detection of CD69 expression as a rapid method for determining poly-and oligo-clonal lymphocyte activation. Clin. Diagn. Lab. Immunol. 3: 301-304

30. Akbar AN, Borthwick NJ, Wickremasinghe RG, Panayiotidis P, Pilling D, Bofill M, Krajewski S, Reed JC and Salmon M (1996) Interleukin-2 receptor common $\gamma$ chain signaling cytokines regulate activated $\mathrm{T}$ cell apoptosis in response to growth factor withdrawal: selective induction of anti-apoptotic $\left(b c l-2, b c l-x_{L}\right)$ but not pro-apoptotic ( $b a x, b c l-x_{S}$ ) gene expression. Eur. J. Immunol. 26: 294-299

31. Reed JC (1994) Bcl-2 and the regulation of programmed cell death. J. Cell Biol. 124: $1-3$

32. Boise LH and Thompson CB (1996) Hierarchical control of lymphocyte survival. Science 274: 67-68

33. Akbar AN, Borthwick N, Salmon M, Gombert W, Bofill M, Shamsadeen N, Pilling D, Pett S, Grundy JE and Janossy G (1993) The significance of low bcl-2 expression by CD45RO T cells in normal individuals and patients with acute viral infections: The role of apoptosis in T cell memory. J. Exp. Med. 178: 427-438

34. Lin JX, Migone TS, Tsang M, Friedmann M, Weatherbee JA, Zhou L, Yamauchi A, Bloom ET, Mietz J, John S and Leonard WJ (1995) The role of shared receptor motifs and common Stat proteins in the generation of cytokine pleiotropy and redundancy by IL-2, IL-4, IL-7, IL-13 and IL-15. Immunity 2: 331-339
35. Miyazaki T, Liu ZJ, Kawahara A, Minami Y, Yamada K, Tsujimoto Y, Barsoumian EL, Permutter RM and Taniguchi T (1995) Three distinct IL-2 signaling pathways mediated by bcl-2, c-myc, and lck cooperate in hematopoietic cell proliferation. Cell 81: 223-231

36. Anderson DM, Kumaki S, Ahdieh M, Bertles J, Tometsko M, Loomis A, Giri J, Copeland NG, Gilbert DJ, Jenkins NA, Valentin V, Kirstein MN, Shapiro DN, Morris SW, Park LS and Cosman D (1995) Functional characterization of the human IL-15 receptor $\alpha$ chain and close linkage of IL15RA and IL2RA genes. J. Biol. Chem. 270: 29862-29869

37. Giri JG, Kumaki S, Ahdieh M, Friend DJ, Loomis A, Shanebeck K, DuBose R, Cosman D, Park LS and Anderson DM (1995) Identification of a novel IL-15 specific binding protein that is structurally related to the $\alpha$-chain of the IL-2R. EMBO J. 14: $3654-3663$

38. Johnson N and Parkin JM (1997) Dysregulation of the interleukin-2 receptor $\alpha$ and $\beta$-chain expression in CD4 and CD8 T cells in HIV infection. Cytometry 30 : $289-295$

39. Naora H and Gougeon M-L (1999). Activation, survival and apoptosis of CD45R0+ and CD45R0 - T cells of HIV-infected individuals: effects of IL-15 and comparison with IL-2. Immunology 97: 181-187

40. Agostini C, Trentin L, Sancetta R, Facco M, Tassinari C, Cerutti A, Bortolin M, Milani A, Siviero M, Zambello R and Semenzato G (1997) Interleukin-15 triggers activation and growth of the CD8 T-cell pool in extravascular tissues of patients with acquired immunodeficiency syndrome. Blood 90: 1115-1123

41. Blair PJ, Boise LH, Perfetto SP, Levine BL, McCrary G, Wagner KF, St Louis DC, Thompson CB, Siegel JN and June CH (1997) Impaired induction of the apoptosis-protective protein bcl- $\mathrm{x}_{\mathrm{L}}$ in activated PBMC from asymptomatic HIVinfected individuals. J. Clin. Immunol. 17: 234-246

42. Strasser A, Harris AW, Huang DCS, Krammer PH and Cory S (1995) Bcl-2 and Fas/APO-1 regulate distinct pathways to lymphocyte apoptosis. EMBO J. 14: $6136-6147$

43. Lacronique V, Mignon A, Fabre M, Viollet B, Bouquet N, Molina T, Porteu A, Henrion A, Bouiscary D, Varlet $P$, Joulin V and Kahn A (1996) Bcl-2 protects from lethal hepatic apoptosis induced by an anti-Fas antibody in mice. Nature Med. 2: 80-86

44. Strack PR, West Frey M, Rizzo CJ, Cordova B, George HJ, Meade R, Ho SP, Corman J, Tritch R and KorantBD (1996) Apoptosis mediated by HIV protease is preceded by cleavage of Bcl-2. Proc. Natl. Acad. Sci. USA 93: 9571-9576

45. Hashimoto F, Oyaizu N, Kalyanaraman VS and Pahwa S (1997) Modulation of $\mathrm{Bcl}-2$ protein by $\mathrm{CD} 4$ cross-linking: $\mathrm{A}$ possible mechanism for lymphocyte apoptosis in human immunodeficiency virus infection and for rescue of apoptosis by interleukin-2. Blood 90: 745-753

46. Boise LH and Thompson CB (1997) Bcl- $x_{\mathrm{L}}$ can inhibit apoptosis in cells that have undergone Fas-induced protease activation. Proc. Natl. Acad. Sci. USA 94: 3759-3764

47. Lorenz H-M, Hieronymus T, Grunke M, Manger B and Kalden JR (1997) Differential role for IL-2 and IL-15 in the inhibition of apoptosis in short-term activated human lymphocytes. Scand. J. Immunol. 45: 660-669

48. Van Parijs L, Ibraghimov A and Abbas AK (1996) The roles of costimulation and Fas in T cell apoptosis and peripheral tolerance. Immunity 4: 321-328

49. Lenardo MJ (1997) The molecular regulation of lymphocyte apoptosis. Semin. Immunol. 9: 1-5

50. Bulfone-Paus S, Durkop H, Paus R, Krause H, Pohl T and Onu A (1997) Differential regulation of human $\mathrm{T}$ lymphocyte functions by IL-2 and IL-15. Cytokine 9: $507-513$ 